Supplement of Atmos. Chem. Phys., 21, 9173-9199, 2021

https://doi.org/10.5194/acp-21-9173-2021-supplement

(C) Author(s) 2021. CC BY 4.0 License.

(c) (1)
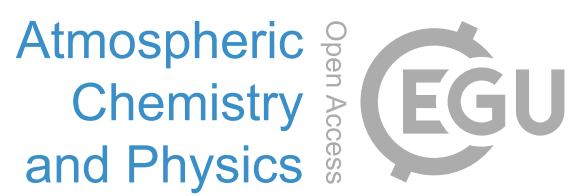

Supplement of

\title{
Mixing state of refractory black carbon aerosol in the South Asian outflow over the northern Indian Ocean during winter
}

\section{Sobhan Kumar Kompalli et al.}

Correspondence to: Surendran Nair Suresh Babu (sureshsplvssc@gmail.com) and Sobhan Kumar Kompalli (sobhanspl@gmail.com)

The copyright of individual parts of the supplement might differ from the article licence. 

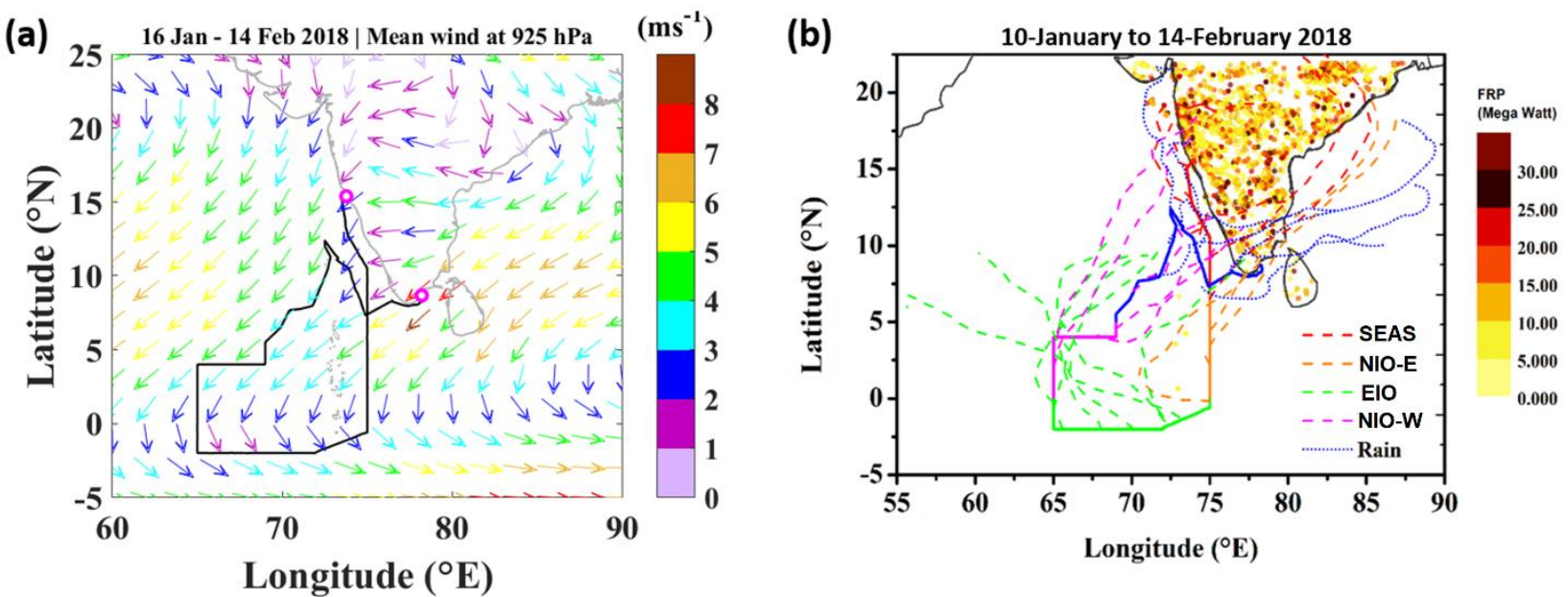

(c) Mean Tropospheric $\mathrm{NO}_{2}$ (molecules $\mathrm{cm}^{-2}$ ) $\mid$ Jan $2018 \times 10^{15}$

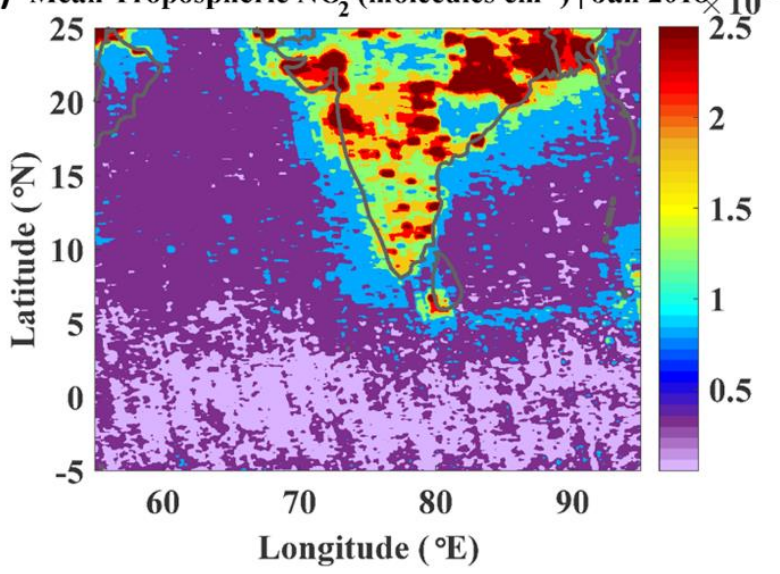

(d) Mean Tropospheric $\mathrm{NO}_{2}$ (molecules $\left.\mathrm{cm}^{-2}\right) \mid$ Feb 2018 $10^{15}$

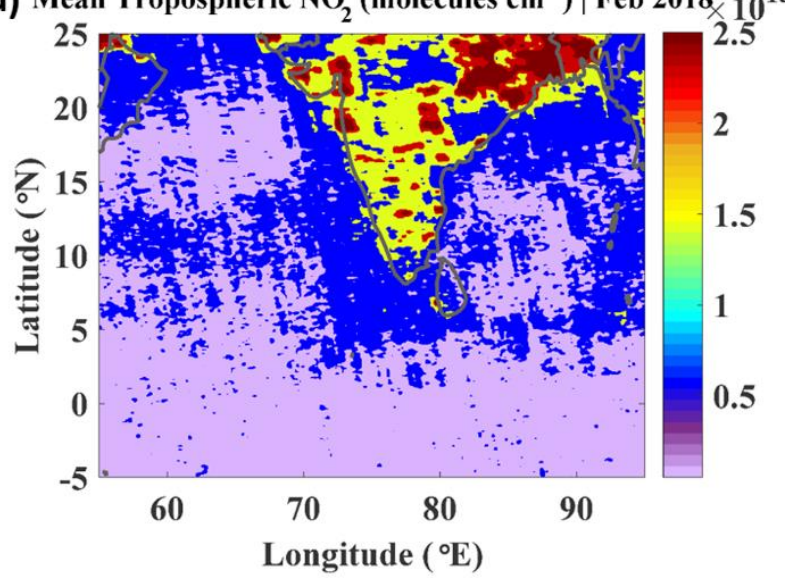

Figure S1.(a) Mean wind vectors at $925 \mathrm{hPa}$ for the experimental period derived from ERA-Interim wind data from ECMWF (European Center for Medium range Weather Forecasting (https://apps.ecmwf.int/datasets/data/interim full-daily/levtype=sfc/) (b) Spatial distribution of Moderate Resolution Imaging Spectroradiometer (MODIS) fire radiative power (MODIS Thermal Anomalies / Fire locations Collection 6 product obtained from https://earthdata.nasa.gov/firms) for the period 10, January to 14, February 2018 along with 5-day air mass back trajectories and the ICARB-2018 cruise track, (c) mean tropospheric $\mathrm{NO}_{2}$ obtained from TROPOspheric Monitoring Instrument (TROPOMI) for January -2018, (d) mean tropospheric $\mathrm{NO}_{2}$ for February -2018 (http://www.temis.nl/airpollution/no2col/no2regio_tropomi.php). 

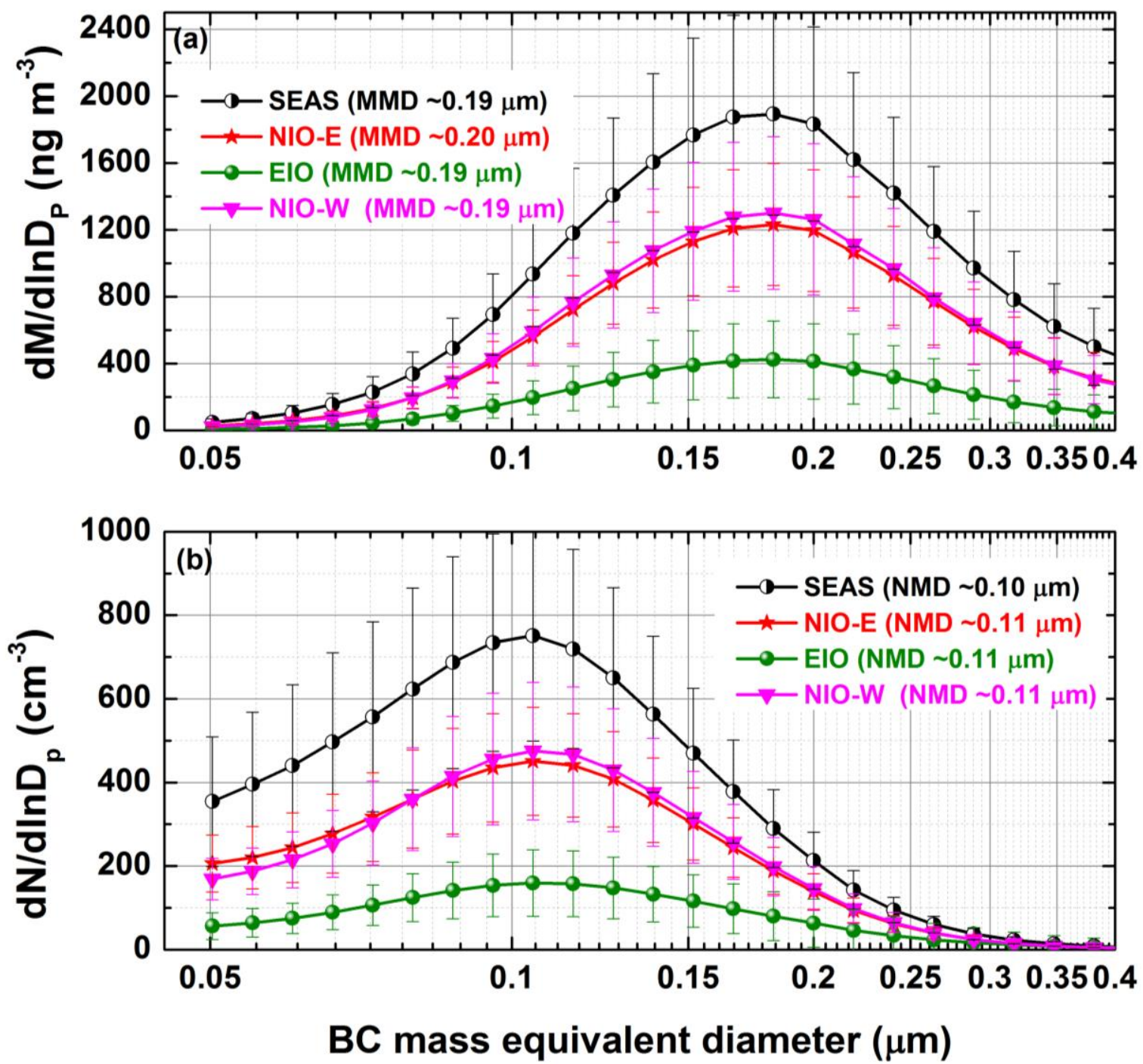

Figure S2. The rBC mass and number size distributions over different regions during the ICARB-2018. The corresponding mean MMD and NMD values are also shown in the figure. The vertical bars indicate standard deviation. 

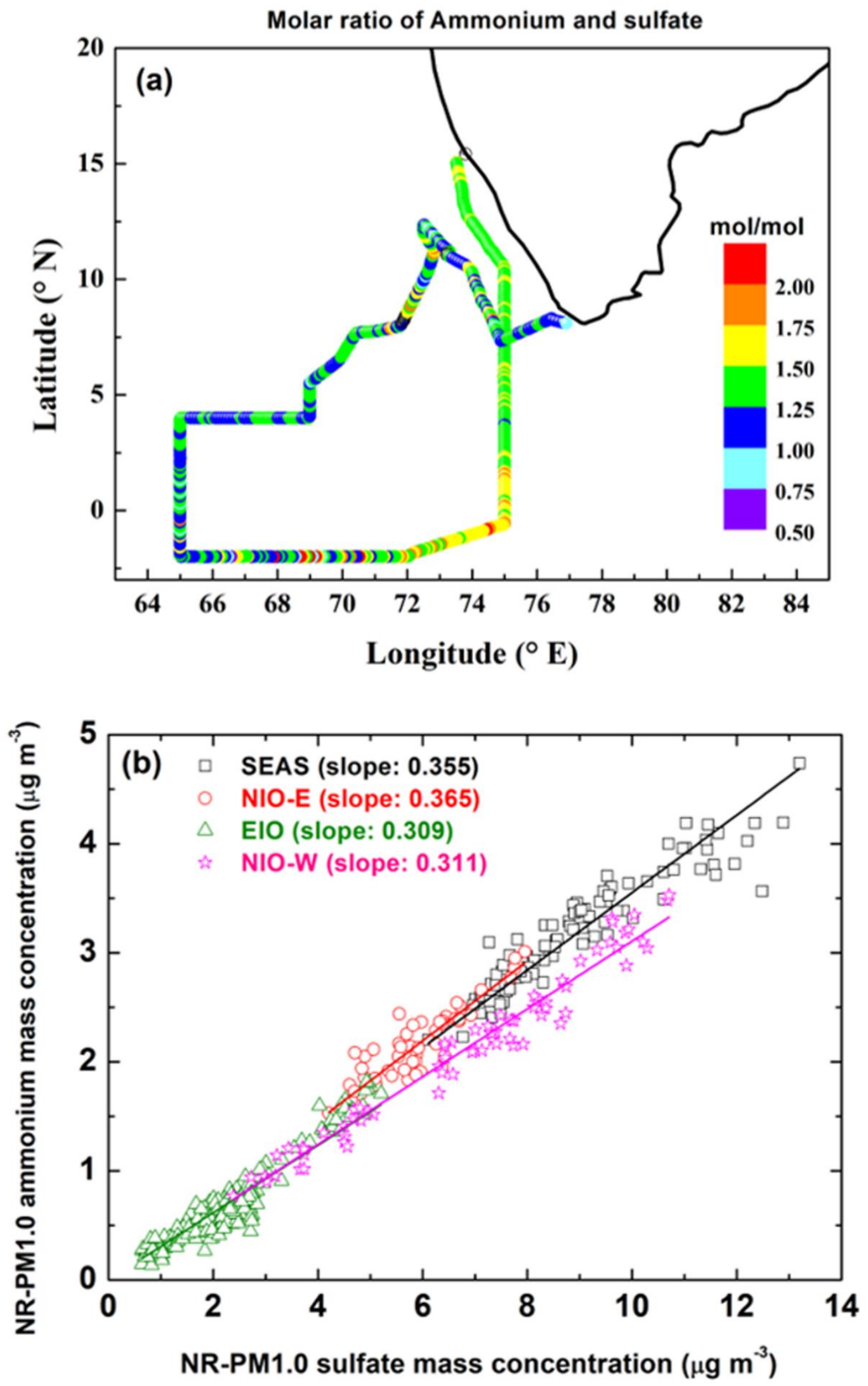

Figure S3.(a) Spatial variation of the molar ratio of ammonium and sulfate (mol/mol);(b) Scatter plot between mass concentrations of NR-PM1.0 sulfate and ammonium during the ICARB-2018. Solid lines represent the linear leastsquares fit to the points, and the value of slope also is written in the panel. 
The mean molar ratios were $\sim 1.44,1.47,1.43$, and $1.25 \mathrm{~mol} / \mathrm{mol}$ over the SEAS, the NIO-E, the EIO, and the NIOW regions, respectively, which indicated an $\mathrm{NH}_{4}{ }^{+}$deficit (Aswini et al., 2020). The spatial variation of molar ratios of ammonium to sulfate is shown in the Supplement (Fig. S3, panel a). The association between submicrometre sulfate and ammonium mass concentrations depicted an excellent correlation (r>0.95) during the ICARB-2018 (Fig. S3b in the

5 Supplement) with varying slopes indicating the extent of neutralization (higher molar ratios and an increased tendency towards neutralization of sulfate near the coastal regions compared far away regions) of sulfate by ammonium. The present observation is consistent with those reported by Aswini et al. (2020), who suggested that just-enough ammonium was present to neutralize sulfate during the ICARB-2018 based on concurrent bulk aerosol chemistry using offline (filter paper sampling) technique. It is possible that when insufficient ammonium is present in the atmosphere, it can lead to the sulfate aerosols existing in forms 10 other than $\left(\mathrm{NH}_{4}\right)_{2} \mathrm{SO}_{4}$. A probable reason for ammonium deficiency could be the difference in the lifetimes of gaseous ammonia and $\mathrm{SO}_{2}$, which are precursors for particulate sulfate and ammonium. Though dominant sources were located over the land for both the precursors, the sulfate aerosol can be formed from the oxidation of transported $\mathrm{SO}_{2}$ over the ocean, whereas ammonia is lost rapidly away from the source regions. This is evident from the varying slopes seen in Fig. S3b. 


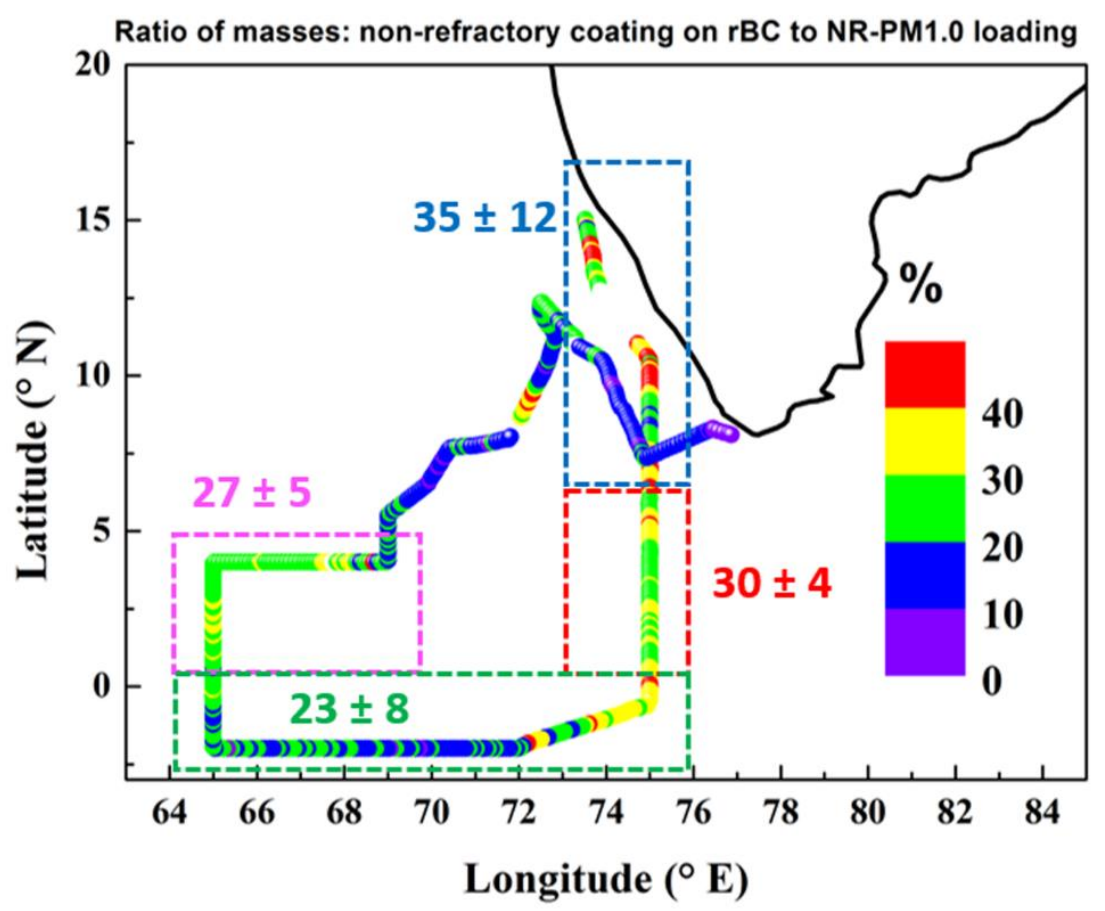

Figure S4: Spatial variation of the ratio (in \%) of non-refractory coating mass on BC to the total mass concentration of non-refractory aerosols during the ICARB-2018. The mean values over different sub-regions are also written in 5 the figure.

Fig.S4 revealed that a substantial portion of the non-refractory submicron aerosol mass is bound to the BC particles over the regions with stronger outflow. While higher mean values of the ratio were observed over the SEAS ( $35 \pm 12 \%)$ and NIO$\mathrm{E}(31 \pm 4)$ regions in the proximity of the sources, as one move away to the farther oceanic EIO, the NR-PM1.0 that is bound 10 to BC particles dropped considerably (mean $23 \pm 8 \%$ ). The values occasionally dropped to as low as 5-6\%, indicating that (a) preferential loss of coating on rBC particle or (ii) a substantial contribution from non-rBC particles to the NR-PM1.0 mass loading due to new particle formation and subsequent growth events (Kompalli et al., 2020b). Though the mean fraction of r-BC containing particles remained similar ( 8\%) over different regions (SEAS, NIO-E and EIO), frequent new particle formation events (Kompalli et al., 2020b) resulted in lower $\mathrm{F}_{\mathrm{BC}}(<2 \%)$ over the EIO region which reflected in the amounts 15 of NR-PM1.0 mass that are bound to rBC particles." 


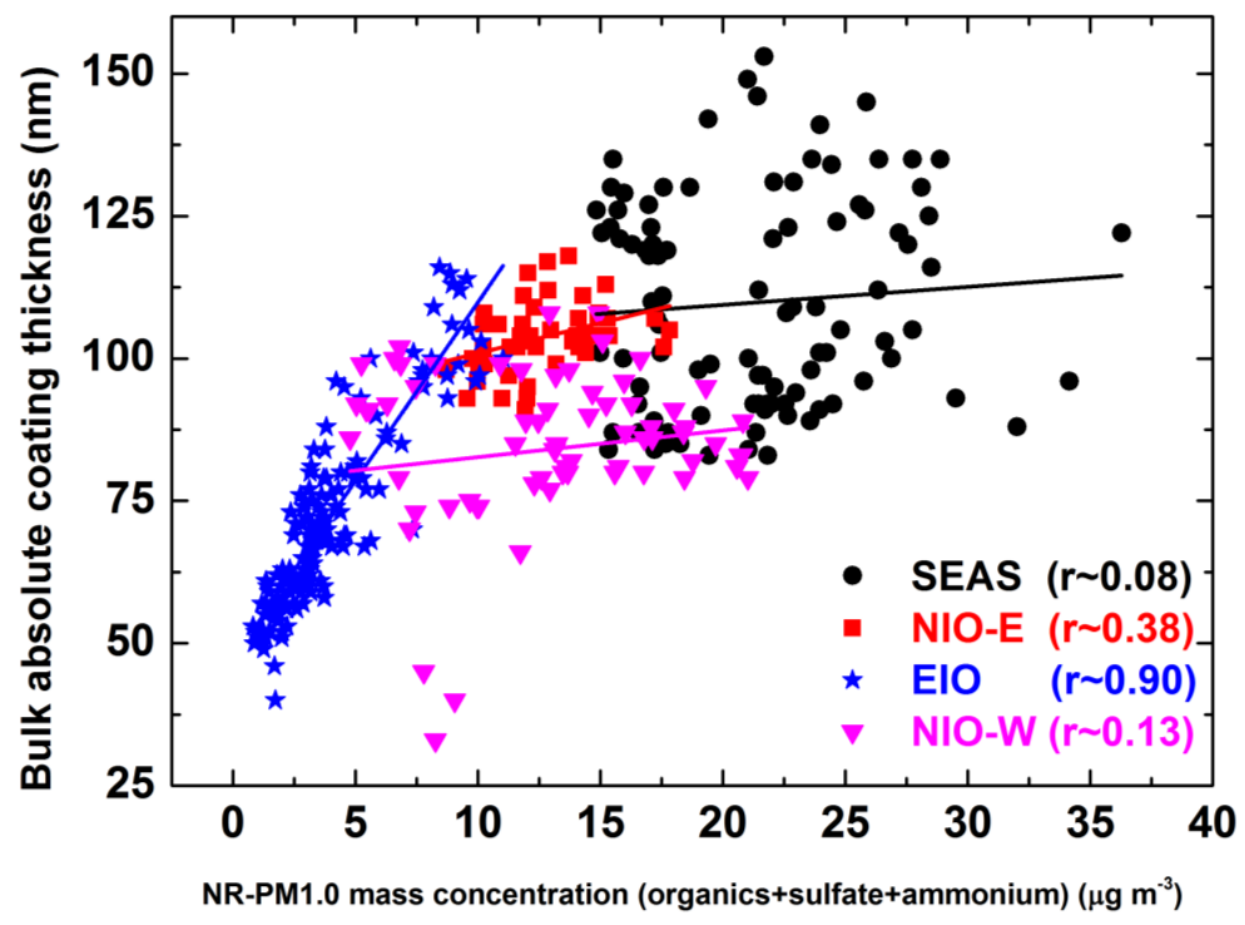

Figure S5: association between the sum of mass concentrations of organics, sulfate, and ammonium aerosols and bulk absolute coating thickness over different sub-regions covered during the ICARB-2018. 
The ICARB-2018 encountered significant weather events with an intense rain (total accumulated rainfall $\sim 57.6 \mathrm{~mm}$ ) affecting the in-situ aerosol measurements and air masses en-route when the cruise was revisiting the SEAS region (the region marked as SAS in Fig. 1) (Gogoi et al., 2019). The wet-scavenging mechanism is one of the effective limiting processes of the lifetime of aerosols (Radke et al., 1980), including BC (Liousseet al., 1996; Chaubey et al., 2010; Kompalli et al., 2014a,b). Given this, though the prevailing air masses still have signatures of the Indian subcontinent, the measurements over the SAS region were not considered as representative of either of the SEAS or the NIO-E regions but treated as a separate case study. The overall mean values of $\mathrm{BC}$ parameters over this region, shown in Table-S1, were interestingly comparable to the values over the SEAS/NIO-E.

10 Table-S1: Mean values of rBC characteristics, including its mixing state parameters in the SAS region affected by the rain due to a significant weather system.

\begin{tabular}{ll}
\hline Parameter & Mean \pm standard deviation \\
\hline rBC mass concentration $\left(\mathrm{ng} \mathrm{m}^{-3}\right)$ & $594 \pm 167$ \\
rBC number concentration $\left(\mathrm{cm}^{-3}\right)$ & $228 \pm 63$ \\
Scattering particle concentration $\left(\mathrm{cm}^{-3}\right)$ & $572 \pm 114$ \\
Mass median diameter $(\mu \mathrm{m})$ & $0.190 \pm 0.006$ \\
Number median diameter $(\mu \mathrm{m})$ & $0.104 \pm 0.004$ \\
Relative coating thickness & $1.77 \pm 0.13$ \\
Absolute coating thickness $(\mathrm{nm})$ & $73 \pm 14$ \\
\hline
\end{tabular}

Further, a severe rainfall event with a total accumulated rainfall of $54.2 \mathrm{~mm}$ was recorded on 07 February 2018 (00:0009:30 hrs). We have examined rBC microphysical properties prior to the rain event (termed as 'Before', period: 06 February 152018 18:00-23:00 hrs) and compared them to the values during and after the episode. Temporal variation of the various BC and associated parameters depicting the impact of rainfall are shown in Fig.S6.
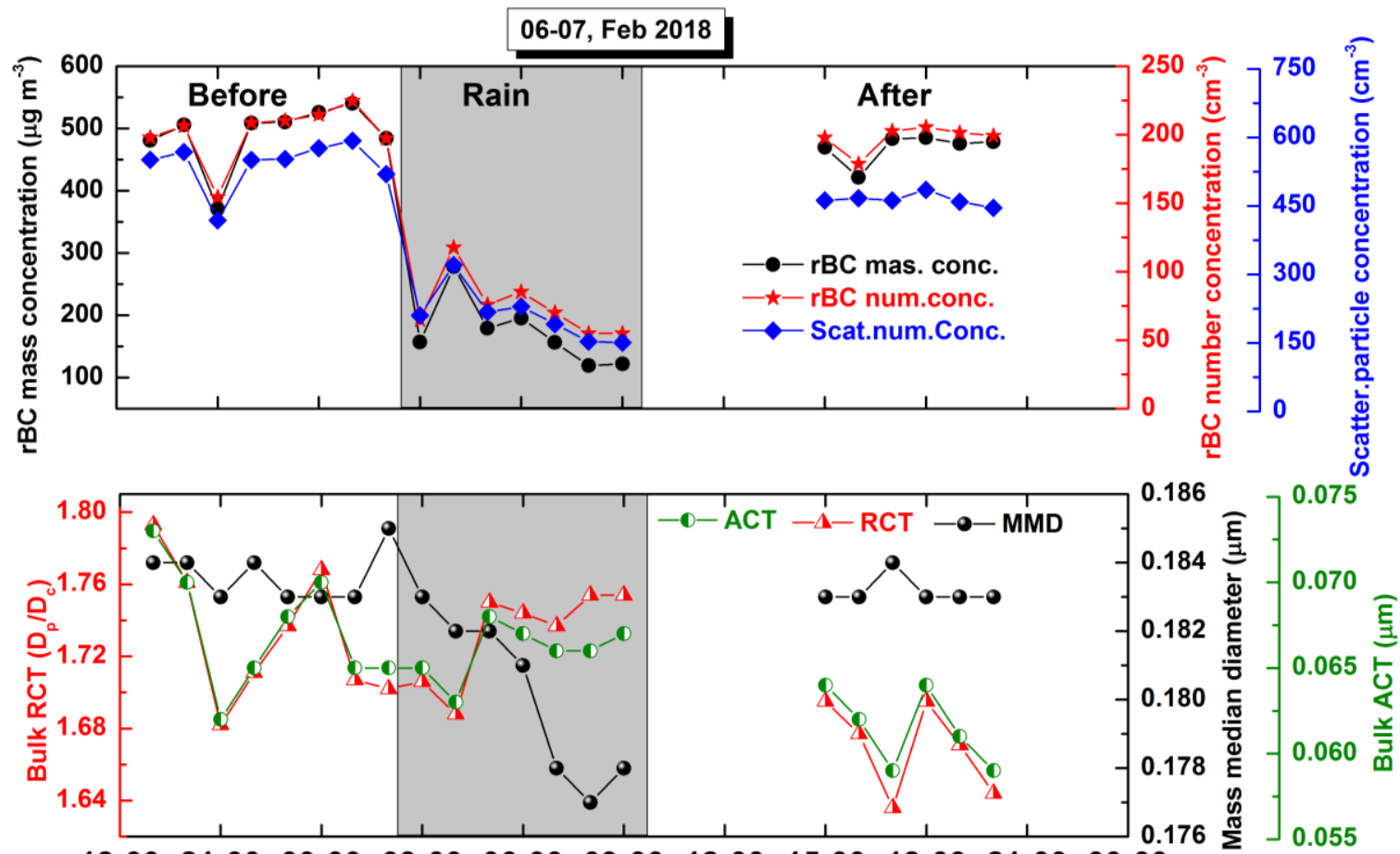

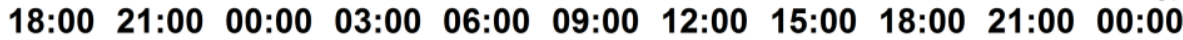

Time (hrs) 
Figure S6. Temporal variation of hourly mean rBC mass, number concentrations, and scattering particle number concentrations (top panel), along with bulk RCT, ACT, and mass median diameters (bottom panel). The shaded portion highlights the rainfall period.

While there is a substantial drop in mass and number concentrations ( $50 \%$ drop during the episode), surprisingly, the BC mixing state parameters (RCT and ACT) showed no such dramatic differences 'before' and during 'rain' events. Even apparent changes in MMD values were minimal (dropped down to $0.177 \mu \mathrm{m}$ from $0.184 \mu \mathrm{m}$ before the event, thus suggesting larger particles were effectively removed due to rain). We have estimated the apparent scavenging efficiency, which is the ratio of the value of the parameter that has been scavenged and its value before the rain (scavenging process) (Gogoi et al., 2019) for different parameters. These are tabulated in Table-S2.

10 Table-S2: Mean values of BC parameters observed during the period of $06^{\text {th }}-07^{\text {th }}$ February 2018 , along with the values of apparent scavenging efficiencies during the rain episode.

\begin{tabular}{llll}
\hline Parameter & Before rain & During rain & Scavenging efficiency \\
\hline rBC mass concentration $\left(\mathrm{ng} \mathrm{m}^{-3}\right)$ & $491 \pm 93$ & $212 \pm 122$ & 0.43 \\
rBC number concentration $\left(\mathrm{cm}^{-3}\right)$ & $202 \pm 36$ & $90 \pm 48$ & 0.46 \\
Scattering particle concentration $\left(\mathrm{cm}^{-3}\right)$ & $544 \pm 91$ & $249 \pm 122$ & 0.46 \\
Mass median diameter $(\mu \mathrm{m})$ & $0.183 \pm 0.003$ & $0.180 \pm 0.006$ & -- \\
Number median diameter $(\mu \mathrm{m})$ & $0.103 \pm 0.000$ & $0.101 \pm 0.002$ & -- \\
Relative coating thickness & $1.74 \pm 0.05$ & $1.73 \pm 0.04$ & -- \\
Absolute coating thickness $(\mathrm{nm})$ & $68 \pm 5$ & $66 \pm 3$ & -- \\
\hline
\end{tabular}

In Fig.S7 in the Supplement, mean BC mass size distributions, before, during, and after the rain period are shown along with the loss in mass concentrations (\% drop) in each size bin. Except for changes in magnitudes, there were no noticeable changes in the MMD of the size distributions due to rain episode.

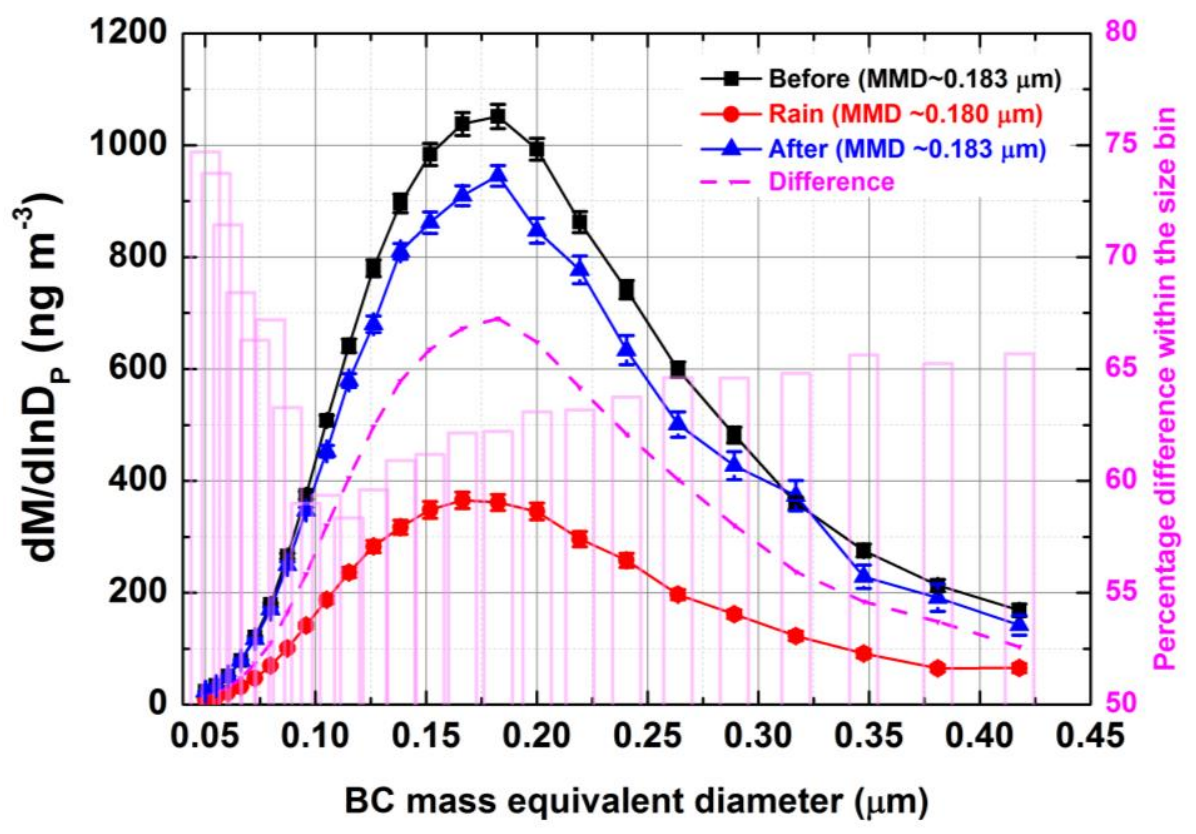

Figure S7. BC Mass size distribution before, during, and after the rainfall episode. The bars show the percentage drop in the $\mathrm{BC}$ mass concentrations due to the rain event.

Even though below-cloud scavenging is a vital sink mechanism for aerosol BC (it reduced the concentrations by almost half), it was less effective in altering the microphysical properties like MMD and mixing state parameters during the present study. 
Detailed analysis of the rainfall characteristics like drop size distributions along with the collection efficiency of the falling raindrop to capture the submicrometre sized $\mathrm{BC}$ particles and prevailing condensable species is required to explain this.

\section{References:}

5 Chaubey, J.P., Moorthy, K.K., Babu, S.S., Nair, V.S., Tiwari, A.: Black-Carbon aerosols over coastal Antarctica and its scavenging by snow during southern hemispheric summer, Journal of Geophysical Research, 115, doi:10.1029/2009/JD013381, 2010.

Kompalli, S.K., Moorthy, K.K., Babu, S.S.: Rapid response of atmospheric BC to anthropogenic sources: observational evidence, Atmospheric Science Letters, 15, 166-171, DOI: 10.1002/as12.483., 2014a.

10 Kompalli, S.K., Babu, S.S., Moorthy, K.K.,.Manoj, M.R, Kirankumar, N.V.P., Shaeb, K.H.B., Joshi, A.K.: Aerosol Black Carbon characteristics over Central India: Temporal variation and its dependence on mixed layer height. Atmospheric Research., 147-148, 27-37, http://dx.doi.org/10.1016/ j.atmosres.2014.04.015, 2014b.

Liousse, C., Penner J.E., Chuang C., Walton, J.J., Eddleman, H., Cachier, H.: A global three-dimensional model study of carbonaceous aerosols. J. Geophys. Res.101, 19411-19432, 1996.

15 Radke, L.M., Ellgrowth, M., Hobbs, P.: Scavenging of aerosol particles by precipitation, Journal of Applied Meteorology, $19,715-722,1980$. 